\title{
Evaluasi Program Gerakan Membangun Desa Sang Bumi Ruwa Jurai: Gerbang Desa Saburai di Provinsi Lampung
}

\section{Program Evaluation of Gerakan Membangun Desa Sang Bumi Ruwa Jurai: Gerbang Desa Saburai in Lampung Provinve}

\author{
Oleh: \\ Leni Sepri Yanti ${ }^{1}$, Ambya ${ }^{1}$, dan I Wayan Suparta ${ }^{1}$ \\ ${ }^{1}$ Fakultas Ekonomi dan Bisnis Universitas Lampung, Lampung, Indonesia \\ "email: leni@umitra.ac.id
}

Received September 13, 2020; Revised December 16, 2020; Accepted December 27, 2020

\begin{abstract}
ABSTRAK
Penelitian ini bertujuan untuk mengevaluasi Program Gerbang Desa Saburai yang telah diterapkan pada tahun 2015-2018 pada 13 kabupaten di Provinsi Lampung. Penelitian ini mengguakan analisis deskriptif kualitatif. Metode yang digunakan dalam penelitian ini adalah analisis data panel yang menggunakan uji signifikansi model Random Effect Model (REM). Hasil penelitian menujukkan bahwa progres pelaksanaan Program Gerbang Desa Saburai Tahun Anggaran 2015-2018 berjalan dengan baik. Program Gerbang Desa Saburai Tahun 2015, terdiri dari desa tertinggal 15 desa. Pada tahun 2016, jumlah desa dalam status kurang berkembang ada 59 desa (59 persen), desa berkembang yaitu 24 desa (24 persen), dan desa maju yaitu 2 desa (2 persen). Pada tahun 2017, jumlah desa kurang berkembang yaitu 143 desa (57.2 persen), desa dengan status berkembang yaitu 57 desa (22,8 persen), dan desa maju yaitu 5 desa (2 persen). Pada tahun 2018, jumlah desa dengan status kurang berkembang yaitu 194 desa (49.36 persen), desa dengan status berkembang sebanyak 139 desa (35.36 persen), Jumlah desa maju sebesar 29 desa (7,37 persen). Hasil regresi menujukkan bahwa Bantuan Langsung Masyarakat dan Swadaya Masyarakat pada Program Gerbang Desa Saburai berpengaruh negatif dan signifikan terhadap jumlah desa tertinggal di 13 kabupaten Provinsi Lampung.
\end{abstract}

Kata kunci: Desa Tertinggal, Evaluasi, Program Desa Saburai, REM

\section{ABSTRACT}

This study aims to evaluate the Gerbang Desa Saburai Program (Saburai Village Gate Program) which has been implemented in 2015-2018 in 13 districts in Lampung Province. This research uses a qualitative descriptive analysis. The method used in this research is panel data analysis using the significance test of the Random Effect Model (REM) model. The results showed that the progress of the implementation of the Gerbang Desa Saburai Program for the 2015-2018 Fiscal Year went well. The 2015 Gerbang Desa Saburai Program, consists of 15 underdeveloped villages. In 2016, the number of villages in underdeveloped status was 59 villages (59 percent), developing villages were 24 villages (24 percent), and developed villages were 2 villages (2 percent). In 2017, the number of underdeveloped villages was 143 villages (57.2 percent), villages with developing status were 57 villages (22.8 percent), and developed villages were 5 villages (2 percent). In 2018, the number of villages with underdeveloped status was 194 villages (49.36 percent), 139 villages with developing status (35.36 percent), the number of developed villages was 29 villages (7.37 percent). The regression results showed that Community Direct Aid and Community Self-Help for the Gerbang Desa Saburai Program had a negative and significant effect on the number of underdeveloped villages in 13 districts of Lampung Province.

Keywords: Underdeveloped Villages, Evaluation, Gerbang Desa Saburai Program, REM 


\section{PENDAHULUAN}

Pengentasan kemiskinan harus pula berarti peningkatan mutu hidup. Itu sebabnya hasil usaha besar seperti pembangunan masyarakat, tidak cukup diukur dengan satu dimensi materiil atau fisik semata (Sumawinata, 2004: 178). Untuk mengatasi persoalan pengangguran, keterbelakangan dan keterpurukan yang menyebabkan sebuah desa menjadi tertinggal diperlukannya serangkaian kebijakan (Torado dan Smith, 2006). Kebijakan tersebut dirancang guna mengoreksi kesalahan-kesalahan agar suatu desa dapat mengalami kemajuan di tengah hiruk-pikuk dunia globalisasi.

Kementerian Desa, Pembangunan Daerah Tertinggal (PDT) dan Transmigrasi, merespon keluarnya Perpres Nomor 131 Tahun 2015 dengan menargetkan pengentasan daerah tertinggal pada Rencana Pembangunan Jarak Menengah Nasional (RPJMN) 2015-2019 sebanyak 80 kabupaten dari total 122 kabupaten yang tertinggal. Target itu berusaha dicapai lewat berbagai program, dengan fokus tiga hal: sarana dan prasarana, pengembangan sumber daya manusia dan pertumbuhan ekonomi.

Peraturan Presiden Nomor 131 Tahun 2015 tentang Penetapan Daerah Tertinggal Tahun 2015 - 2019 disebutkan, daerah tertinggal adalah daerah kabupaten yang wilayah serta masyarakatnya kurang berkembang dibandingkan dengan daerah lain dalam skala nasional. Pada Peraturan Kementerian Desa, Pembangunan Daerah Tertinggal dan Transmigrasi No.3 Tahun 2015 tentang Petunjuk Teknis Penentuan Indikator Daerah Tertinggal secara Nasional, suatu daerah ditetapkan sebagai daerah tertinggal berdasarkan kriteria : perekonomian masyarakat, sumber daya manusia, sarana dan prasarana, kemampuan keuangan daerah, aksesibiltas, dan karakteristik daerah.

Pada tahun 2014 Badan Pusat Statistik (BPS) Provinsi Lampung telah menetapkan adanya 380 Desa kategori Tertinggal yang masih sangat memerlukan perhatian khusus. Sejalan dengan Agenda Nawa Cita, "membangun Indonesia dari pinggiran dengan memperkuat daerah dan desa dalam Negara Kesatuan" dan pencapaian visi Gubernur Lampung, Lampung Maju dan Sejahtera, Tahun 2019. Pemerintah Provinsi Lampung memandang perlu mengembangkan kebijakan program untuk mendorong adanya program pembangunan dari, oleh, dan untuk masyarakat di lokasilokasi desa tertinggal dengan memanfaatkan potensi dan pranata sosial khas yang ada di Provinsi Lampung.

Agar kebijakan program pembangunan ini dapat dilihat sebagai suatu Model Pembangunan Berbasis Masyarakat yang berciri khas di wilayah Provinsi Lampung, maka Program pemberian bantuan dana stimulan tersebut diberi nama Program Gerakan Membangun Desa Sai Bumi Ruwa Jurai yaitu suatu gerakan yang dilakukan dari, oleh, dan untuk masyarakat di Provinsi Lampung agar secara bersama dalam upaya mempercepat pembangunan infrastruktur desa bagi pengembangan otonomi masyarakat Desa di lokasi-lokasi desa tertinggal.

Program penanggulangan desa tertinggal Gerbang Desa Saburai dilaksanakan di Provinsi Lampung sebagai upaya pemerintah untuk membangun kemandirian masyarakat dalam menanggulangi kemiskinan secara berkelanjutan. Program ini di mulai sejak 2015 yang merupakan salah satu program unggulan Provinsi Lampung dalam rangka membangun desa dengan tujuan mengentaskan desa tertinggal. Provinsi Lampung memiliki 2.435 desa, dan 1.302 masuk dalam kategori desa tertinggal.

Pemerintah Provinsi Lampung di bawah pimpinan Gubernur Ridho Ficardo membuat suatu program unggulan yaitu Program Gerakan Membangun Desa Sai Bumi Ruwai Jurai atau disebut dengan Gerbang Desa Saburai yang diresmikan sejak tahun 2015 yang tertuang dalam Peraturan Gubernur nomor 37 tahun 2015 tentang Program Membangun Desa Sai Bumi Ruwa Jurai Tahun 2015 - 2018. Diawal penyelenggaraannya, program pemerintah 
Provinsi Lampung memberikan dana bantuan kepada 30 desa tertinggal sebesar 100 juta rupiah tiap desa, dana tersebut dimaksudkan untuk memberikan stimulan bagi desa, demi tercapainya desa yang makmur dan sejahtera, tertinggal dan transmigrasi). Program Gerbang Desa Saburai adalah salah satu program unggulan di Provinsi Lampung dalam rangka membangun desa dan mengentaskan desa tertinggal.

Pelaksanaan Program Gerbang Desa pada kenyataannya tidak berjalan dengan lancar, hal tersebut terlihat dari hasil evaluasi Program Gerbang Desa Saburai yang dilakukan oleh pemerintah ditemukan beberapa kelemahan dalam pelaksanaan Program Gerbang Desa Saburai pada tahun 2015 dan 2016, yaitu sebagai berikut. Pertama, di tahun 2016 pelaksanaan program ini belum optimal dan efektif, karena ada beberapa petunjuk teknis dalam pelaksanaan Gerbang Desa Saburai yang harus diperbaiki lagi dari petunjuk teknis yang sudah ada sebelumnya di tahun 2015. (http://www.forumdesa.com/201/09/agarma syarakat- tidak-di-rugikan.html diakses pada tanggal 09 Oktober 2017).

Prasetyanto (2012), hasil kajiannya menunjukkan alokasi dana desa mampu meningkatkan kinerja fiskal dan perekonomian daerah, mampu mengurangi jumlah penduduk miskin dan meningkatkan produk domestik regional bruto sektor pertanian. Untuk membantu kelancaran dan keberhasilan Program Gerbang Desa Saburai dibantu oleh fasilitator desa. Setiap desa lokasi Program Gerbang Desa Saburai akan didampingi oleh 1 (satu) orang Fasilitator Desa (FD).

Effendi (2007) menyatakan bahwa hasil kegiatan pemberdayaan dalam Gerakan pembangunan Beguai Jejama Sai Betik (BJSB) di Kabupaten Lampung Barat, Jejamou Ngebangun Sai Bumi Nengah Nyepur (JN-SBNN) di Kabupaten Tulang Bawang Barat dan Gerakan Membangun Tapis Berseri (Gemma Tapis) di Kota Bandar Lampung, secara umum partisipasi masyarakat dalam merencanakan dan memutuskan sendiri program pembangunan dalam kategori sedang, menyumbang materi dan swadaya dalam kategori tinggi, menyumbang menyumbang tenaga dalam pelaksanaan kegiatan dalam kategori sedang, monitoring dan evaluasi kegiatan dalam kategori sedang serta menikmati dan memanfaatkan hasil pembangunan dalam kategori sedang

Bayu, Putra, Mahaendra \& Yuliarmi (2017) menunjukkan bahwa Program PNPM Mandiri Perkotaan bidang infrastruktur berpengaruh positif terhadap terhadap produktivitas Kecamatan Denpasar Utara. Program PNPM mandiri perkotaan berpengaruh positif terhadap kesejahteraan masyarakat PNPM Mandiri.

Rumusan masalah dalam penelitian ini adalah bagaimanakah uotput Program Gebang Desa Saburai di Provinsi Lampung. Tujuan penelitian ini adalah untuk mengevaluasi Program Geban Desa Saburai di 13 kabupaten periode 2015-2018.

\section{METODE PENELITIAN}

Data yang digunakan adalah data panel dengan menggunakan jenis data sekunder, yaitu data yang diperoleh berdasarkan informasi yang telah disusun dan dipublikasikan oleh instansi tertentu. Data dimulai dari tahun 2015 sampai 2018 pada 13 kabupaten di Provinsi Lampung. Jumlah observasi pada penelititan adalah sebanyak 52 observasi dengan menggunakan gabungan antara data time series dan data cross section. Data diperoleh dari Badan Pusat Statistik dan sumber lainnya.

\section{Metode Analisis Data}

Studi ini mengevaluasi output yang dihasilkan dengan menganalisis perubahan status desa dengan menggunakan statistik deskriptif. Dengan kategori Desa Berkembang terkait dengan situasi dan kondisi dalam status Desa Tertinggal dan Desa kurang Berkembang dapat dijelaskan dengan faktor kerentanan. Apabila ada tekanan faktor kerentanan, seperti terjadinya goncangan ekonomi, bencana alam, ataupun 
konflik sosial maka akan membuat status Desa Kurang Berkembang jatuh turun menjadi Desa Tertinggal. Dan biasanya, jika faktor bencana alam tanpa penanganan yang cepat dan tepat, atau terjadinya konflik sosial terus terjadi berkepanjangan maka sangat potensial berdampak menjadikan Desa Kurang Berkembang turun menjadi Desa Tertinggal. Sementara itu, kemampuan Desa Berkembang mengelola daya, terutama terkait dengan potensi, informasi/nilai, inovasi/prakarsa, dan kewirausahaan akan mendukung gerak kemajuan Desa Berkembang menjadi Desa Maju (PERMENDES, 2016).

\section{Variabel Penelitian}

Variabel independen dalam penelitian ini: (1) Bantuan Langsung Masyarakat Program Gerbang Saburai (2) Swadaya Masyarakat pada Program Gerbang Saburai, Variabel dependen dalam penelitian ini adalah Desa Tertinggal

Tabel 1.

Nama Variabel, Simbol Variabel, Ukuran, dan Sumber Data

\begin{tabular}{lccc}
\hline \multicolumn{1}{c}{$\begin{array}{c}\text { Nama } \\
\text { Variabel }\end{array}$} & $\begin{array}{c}\text { Simbol } \\
\text { Variabel }\end{array}$ & $\begin{array}{c}\text { Satuan } \\
\text { Pengukuran }\end{array}$ & Sumber Data \\
\hline $\begin{array}{l}\text { Desa } \\
\text { Tertinggal } \\
\text { Bantuan }\end{array}$ & $\mathrm{Y}$ & Jumlah & $\begin{array}{c}\text { Badan Pusat } \\
\text { Statistik }\end{array}$ \\
$\begin{array}{l}\text { Langsung } \\
\text { Masyarakat }\end{array}$ & $\mathrm{X}_{1}$ & Rupiah & $\begin{array}{c}\text { BAPPEDA } \\
\text { Swadaya } \\
\text { Masyarakat }\end{array}$ \\
& $\mathrm{X}_{2}$ & Rupiah & Laporan KMP \\
Sumber: Olahan Peneliti, 2019 &
\end{tabular}

\section{Metode Analisis Regresi}

Studi ini menggunakan analisis panel data atau pooled data. Data panel adalah gabungan antara data runtut waktu (time series) dan data silang (cross section). Pengolahan data menggunakan program Eviews 9. Secara standar dalam penggunaan data panel akan dibangun tiga pendekatan yaitu: common effect, fixed effect, dan random effect. Analisis dalam penelitian ini diterapkan melalui pendekatan deskriptif kuantitatif untuk mengetahui pengaruh variabel bebas terhadap variabel terikat menggunakan regresi linear berganda dan uji asumsi klasik.

Faktor-faktor yang diduga mempengaruhi desa tertinggal adalah dana BLM (X1), Swadaya masyarakat (X2), secara matematis model yang digunakan adalah sebagai berikut :

Model Regresi :

$$
\mathrm{JDT}_{\mathrm{it}}=\beta_{0}+\beta_{1} \mathrm{BLM}_{\mathrm{it}}+\beta_{2} \mathrm{SDY}_{\mathrm{it}}+\varepsilon_{\mathrm{it}}
$$

dimana:

$\mathrm{JDT}_{\text {it }}=$ Jumlah Desa Tertinggal

$\beta_{\mathrm{i}} \quad=$ Konstanta

$\mathrm{BLM}_{\mathrm{it}}=$ Bantuan Langsung Masyarakat

$\mathrm{SDY}_{\text {it }}=$ Swadaya Masyarakat

$\varepsilon_{\mathrm{it}} \quad=$ error term

\section{HASIL DAN PEMBAHASAN}

\section{Evaluasi Program}

Progres pelaksanaan Program Gerbang Desa Saburai Tahun Anggaran 2015 berjalan dengan baik, hal ini ditandai dengan progres seluruh desa yaitu $100 \%$ selesai. Jumlah dana yang disalurkan dengan jumlah bantuan Rp3.000.000.000. Program Gerbang Desa Saburai Tahun 2015, terdiri dari desa tertinggal (15 desa), desa kurang berkembang (10 desa) dan desa berkembang (5 desa).

Progres pelaksanaan Program Gerbang Desa Saburai Tahun Anggaran 2016 berjalan dengan baik, hal ini ditandai dengan progres seluruh desa yaitu $100 \%$ selesai. Jumlah dana yang disalurkan dengan jumlah bantuan Rp30.000.000.000. Jumlah desa dalam status kurang berkembang ada 59 desa (59 persen), desa berkembang yaitu 24 desa ( 24 persen), dan desa maju yaitu 2 desa ( 2 persen)

Progres pelaksanaan Program Gerbang Desa Saburai Tahun Anggaran 2017 berjalan dengan baik, hal ini ditandai dengan progres 249 desa yaitu $100 \%$ selesai dan 1 desa baru menyelesaikan $95 \%$ pekerjaan dan laporan pertanggungjawaban dana tahap akhir belum diselesaikan. Desa tersebut adalah Pekon Serungkuk Kecamatan Belalau Kabupaten Lampung Barat. Jumlah desa kurang berkembang yaitu 143 desa (57.2 persen), 
desa dengan status berkembang yaitu 57 desa (22,8 persen), dan desa maju yaitu 5 desa ( 2 persen).

Progres pelaksanaan Program Gerbang Desa Saburai Tahun Anggaran 2018 berjalan dengan baik, hal ini ditandai dengan jumlah desa yang didanai yaitu 393 desa. Pencairan dana Program Gerbang Desa Saburai Tahun Anggaran 2018 melalui tiga tahap yaitu. Pertama, sebesar 40\% pada tanggal : 4 Juni 2019. Kedua, Seharusnya setelah proses pencairan Dana Tahap pertama dan pelaksanaan kegiatan serta pertanggungjawaban penggunaan Dana Tahap Pertama selesai dilaksanakan; desadesa dapat mengajukan pencairan dana tahap kedua (40\%) dan pelaksanaan pekerjaan tahap kedua, pertanggungjawaban dana tahap kedua serta mengajukan lagi pencairan dana tahap ketiga (terakhir) 20\%. Jumlah desa dengan status kurang berkembang yaitu 194 desa (49.36 persen), desa dengan status berkembang sebanyak 139 desa (35.36 persen), Jumlah desa maju sebesar 29 desa (7,37 persen).

\section{Evaluasi Kinerja Program Gerbang Desa Saburai 2015}

1. Sinkronisasi, Koordinasi, Sinergisitas Program Gerbang Desa Saburai tahun 2015

Tabel 2.

Sinkronisasi, Koordinasi, Sinergisitas 2015

\begin{tabular}{cc}
\hline Tujuan & Kategori \\
\hline Sinkronisasi & Rendah \\
Koordinasi & Rendah \\
Sinergisitas & Rendah \\
\hline
\end{tabular}

Keterangan : R= Rendah $\quad \mathrm{S}=$ Sedang $\quad \mathrm{T}=$ Tinggi

Sumber : Olahan Peneliti 2019

2. Partisipasi Masyarakat Dalam

Pembangunan Program Gerbang Desa Saburai tahun 2015
Tabel 3.

Tingkat Partisipasi Masyarakat 2015

\begin{tabular}{lc}
\hline Partisipasi & Kategori \\
\hline Perencanaan & Rendah \\
Swadaya Masyarakat & Rendah \\
Pelaksanaan & Rendah \\
Monitoring dan Evaluasi & Rendah \\
Menerima manfaat & Sedang \\
\hline
\end{tabular}

Keterangan : R= Rendah $\mathrm{S}=$ Sedang $\mathrm{T}=$ Tinggi

Sumber : Olahan Peneliti 2019

3. Persentase Swadaya Masyarakat Dalam Pembangunan Program Gerbang Desa Saburai tahun 2015

\section{Tabel 4.}

Persentase Swadaya Masyarakat 2015

\begin{tabular}{lc}
\hline Sumber & \multicolumn{1}{c}{ Nilai } \\
\hline $\begin{array}{l}\text { APBD (Rupiah) } \\
\begin{array}{l}\text { Swadaya Masyarakat } \\
\text { (Rupiah) }\end{array}\end{array}$ & 3.000 .000 .000 \\
\hline Jumlah (Rupiah) & 330.000 .000 \\
\hline $\begin{array}{l}\text { Persentase Swadaya } \\
\text { Masyarakat (Persen) }\end{array}$ & 11,00 \\
\hline $\begin{array}{l}\text { Keterangan : R= Rendah S = Sedang } \\
\text { Sumber : Olahan Peneliti 2019 }\end{array}$ & T = Tinggi \\
\end{tabular}

4. Tingkat Partisipasi Tenaga Kerja dan Pendapatan Masyarakat Dalam Pembangunan Program Gerbang Desa Saburai tahun 2015

Tabel 5.

Partisipasi Tenaga Kerja 2015

\begin{tabular}{ccr}
\hline $\begin{array}{c}\text { Tenaga Kerja } \\
(\mathrm{HOK})\end{array}$ & $\begin{array}{c}\text { Upah Minimum } \\
(\mathrm{Rp})\end{array}$ & $\begin{array}{c}\text { Pendapatan } \\
\text { Masyarakat }(\mathrm{Rp})\end{array}$ \\
\hline $14.271,43$ & 70.000 & 999.000 .000 \\
\hline Sumber : Olahan Peneliti 2019 &
\end{tabular}

\section{Evaluasi Kinerja Program Gerbang Desa Saburai 2016}

1. Sinkronisasi, Koordinasi, Sinergisitas Program Gerbang Desa Saburai tahun 2016 
Tabel 6.

Sinkronisasi, Koordinasi, Sinergisitas 2016

\begin{tabular}{|c|c|}
\hline Tujuan & Kategori \\
\hline Sinkronisasi & Rendah \\
\hline Koordinasi & Rendah \\
\hline Sinergisitas & Sedang \\
\hline
\end{tabular}

Sumber : Olahan Peneliti 2019

2. Partisipasi Masyarakat Dalam Pembangunan Program Gerbang Desa Saburai tahun 2016

Tabel 7.

Tingkat Partisipasi Masyarakat 2016

\begin{tabular}{ll}
\hline \multicolumn{1}{c}{ Partisipasi } & Kategori \\
\hline Perencanaan & Rendah \\
Swadaya Masyarakat & Sedang \\
Pelaksanaan & Sedang \\
Monitoring dan Evaluasi & Sedang \\
Menerima manfaat & Sedang \\
\hline Keterangan : R= Rendah S S Sedang & $\mathrm{T}=$ Tinggi \\
Sumber : Olahan Peneliti 2019 &
\end{tabular}

3. Persentase Swadaya Masyarakat Dalam Pembangunan Program Gerbang Desa Saburai tahun 2016

Tabel 8.

Persentase Swadaya Masyarakat 2016

\begin{tabular}{lr}
\hline Sumber & Nilai \\
\hline APBD & 30.000 .000 .000 \\
Swadaya Masyarakat & 3.600 .000 .000 \\
\hline Jumlah (Rupiah) & 33.600 .000 .000 \\
\hline $\begin{array}{l}\text { Persentase Swadaya } \\
\text { Masyarakat (Persen) }\end{array}$ & 12,00 \\
\hline $\begin{array}{l}\text { Keterangan : R= Rendah S = Sedang } \\
\text { Sumber : Olahan Peneliti 2019 }\end{array}$ & \\
& \\
4. Tingkat Partisipasi Tenaga & Kerja dan \\
Pendapatan Masyarakat & Dalam \\
Pembangunan Program 2016 &
\end{tabular}

Tabel 9.

Partisipasi Tenaga Kerja 2016

\begin{tabular}{ccc}
\hline $\begin{array}{c}\text { Tenaga Kerja } \\
(\mathrm{HOK})\end{array}$ & $\begin{array}{c}\text { Upah Minimum } \\
(\mathrm{Rp})\end{array}$ & $\begin{array}{c}\text { Pendapatan } \\
\text { Masyarakat (Rp) }\end{array}$ \\
\hline $134.820,00$ & 75.000 & 10.080 .000 .000 \\
\hline
\end{tabular}

Sumber : Olahan Peneliti 2019
Evaluasi Kinerja Program Gerbang Desa Saburai 2017

1. Sinkronisasi, Koordinasi, Sinergisitas Program Gerbang Desa Saburai 2017

Tabel 10.

Sinkronisasi, Koordinasi, Sinergisitas 2017

\begin{tabular}{cc}
\hline Tujuan & Kategori \\
\hline Sinkronisasi & Sedang \\
Koordinasi & Sedang \\
Sinergisitas & Sedang \\
\hline
\end{tabular}

Keterangan : $\mathrm{R}=$ Rendah $\mathrm{S}=$ Sedang $\mathrm{T}=$ Tinggi Sumber : Olahan Peneliti 2019

2. Partisipasi Masyarakat Dalam Pembangunan Program Gerbang Desa Saburai tahun 2017

Tabel 11.

Tingkat Partisipasi Masyarakat 2017

\begin{tabular}{lc}
\hline Partisipasi & Kategori \\
\hline Perencanaan & Sedang \\
Swadaya Masyarakat & Tinggi \\
Pelaksanaan & Sedang \\
Monitoring dan Evaluasi & Sedang \\
Menerima manfaat & Tinggi \\
\hline Keterangan : R= Rendah S $=$ Sedang & T = Tinggi \\
Sumber : Olahan Peneliti 2019 &
\end{tabular}

3. Persentase Swadaya Masyarakat Dalam Pembangunan Program Gerbang Desa Saburai tahun 2017

Tabel 12.

Persentase Swadaya Masyarakat 2017

\begin{tabular}{lr}
\hline Sumber & \multicolumn{1}{c}{ Nilai $(\mathrm{Rp})$} \\
\hline APBD & 60.000 .000 .000 \\
Swadaya Masyarakat & 7.742 .400 .000 \\
\hline Jumlah & 67.742 .400 .000 \\
\hline Persentase Swadaya & \\
Masyarakat (Persen) & 12,90 \\
\hline Keterangan : R= Rendah S = Sedang & $\mathrm{T}=$ Tinggi \\
Sumber : Olahan Peneliti 2019
\end{tabular}

4. Tingkat Partisipasi Tenaga Kerja dan Pendapatan Masyarakat Dalam Pembangunan Program Gerbang Desa Saburai tahun 2017 
metode random effect (REM) lebih baik digunakan daripada metode fixed effect (FEM) dalam penelitian ini.

Uji Signifikansi Panel Least Squares (Uji Breusch-Pagan LM)

Tabel 20. Hasil LM-Test

\begin{tabular}{lrrr}
\hline \multicolumn{4}{c}{ Test Hypothesis } \\
\hline Breusch- & Cross-section & \multicolumn{1}{c}{ Time } & \multicolumn{1}{c}{ Both } \\
Pagan & 2.593539 & 41.25304 & 43.84658 \\
& $(0.1073)$ & $(0.0000)$ & $(0.0000)$ \\
\hline
\end{tabular}

Sumber: Output Eviews 9

Berdasarkan Tabel 20 dapat dilihat hasil bahwa nilai probabilitas BreuschPagan BP) sebesar 0,0000 lebih kecil dari taraf signifikansi 5\% menunjukkan bahwa nilai probabilitas (p-value) $<0,05$ maka disimpulkan bahwa metode Random Effect (REM) lebih baik dari pada metode Common Effect (CEM) untuk menganalisis data pada penelitian ini.

\section{Pengujian Asumsi Klasik}

\section{Hasil Uji Multikolinieritas}

Dari uji multikolinieritas dihasilkan bahwa tidak ada variabel yang memiliki nilai lebih dari 0.85 maka dari itu hal ini berarti dapat disimpulkan bahwa pada variabel yang digunakan tidak ada multikolinieritas atau dengan kata lain tidak ada hubungan yang linier antar variabel independen yang digunakan dalam penelitian ini.

\section{Hasil Uji Heteroskedastisitas}

Berdasarkan hasil

uji

heteroskedastisitas terlihat bahwa residual tidak menunjukan pola tertentu, sehingga dapat disimpulkan bahwa residual terdeteksi tidak menunjukan heteroskedastisitas.

\section{Hasil Regresi}

Berdasarkan hasil regresi dengan model Random Effect Model seperti Lampiran 4, maka menghasilkan hasil regresi sebagai berikut:

$$
\begin{aligned}
\text { JDT }_{\text {it }}= & 3,944069-0,0983 \mathrm{BLM}_{\mathrm{it}}- \\
& 0,04733 \mathrm{SDY}_{\mathrm{it}} \\
= & (1,796752) \quad(-6,986640) \\
\mathrm{t}_{\text {statistik }} & (-6,192751)
\end{aligned}
$$

Berdasarkan hasil tersebut dapat dilihat bahwa nilai koefisien konstanta adalah 3,944069, hal ini menjelaskan bahwa ketika semua variabel sama dengan nol, maka jumlah desa tertinggal sebanyak 4 desa. Sedangkan koefisien variabel bantuan langsung masyarakat sebesar -0,0983 dengan probabilitas 0,0000 lebih kecil dibandingkan dengan $\alpha=5 \%$, hal ini menujukkan bahwa bantuan langsung masyarakat berpengaruh negatif dan signifikan terhadap jumlah desa tertinggal. Total dana bantuan langsung masyarakat yang dikeluarkan selama 20152018 sebesar Rp152.320.000.000,- dan berhasil mengentaskan desa tertinggal sebanyak 362 desa sehingga untuk mengentaskan satu desa tertinggal diperlukan biaya sebesar Rp.420.773.481,-Selanjutnya koefisien variabel swadaya masyarakat sebesar $-0,04733$ dengan probabilitas 0,0000 lebih kecil dibandingkan dengan $\alpha=5 \%$, hal ini menujukkan bahwa swadaya masyarakat berpengaruh negatif dan signifikan terhadap jumlah desa tertinggal. Total swadaya masyarakat yang dikeluarkan sebasar Rp21.850.800.000,dengan total desa 362 yang berhasil berubah status sehingga untuk satu desa diperlukan biaya Rp60.361.326,-.

\section{Uji Hipotesis Statistik}

\section{Uji-t Parsial}

Tabel 21.

Hasil Uji-t

\begin{tabular}{lccc}
\hline Variabel & t-statistik & t-tabel & Kesimpulan \\
\hline Bantuan & - & - & tolak $\mathrm{H}_{0}$ \\
Langsung & 6,986640 & 1,67655 & \\
Masyarakat & & & \\
\hline Swadaya & - & - & tolak H \\
Masyarakat & 6,192751 & 1,67655 & \\
\hline Sumber: Hasil Eviews 9, 2019 &
\end{tabular}


Pengujian ini bertujuan untuk mengetahui pengaruh dari setiap variabel bantuan langsung masyarakat dan swadaya masyarakat secara parsial terhadap jumlah desa teringgal. Dengan menggunakan signifikansi 5\% $(\alpha=0,05)$, dan df $(n-k-1)=$ 49 diperoleh t-tabel sebesar 1,67655.

Secara parsial variabel bantuan langsung masyarakat berpengaruh negatif dan signifikan terhadap jumlah desa tertinggal, hal ini ditunjukkan dengan nilai thitung sebesar $-6,986640$ lebih besar dibandingkan dengan nilai t-tabel sebesar 1,67655 sehingga $\mathrm{H}_{0}$ ditolak dan $\mathrm{H}_{\mathrm{a}}$ diterima. Begitu pula dengan variabel swadaya masyarakat berpengaruh negatif dan signifikan terhadap jumlah desa tertinggal, hal ini ditunjukkan dengan nilai t-hitung sebesar -6,986640 lebih besar dibandingkan dengan nilai t-tabel sebesar -1,67655 sehingga $\mathrm{H}_{0}$ ditolak dan $\mathrm{H}_{\mathrm{a}}$ diterima.

\section{Uji F-statistik}

Pada pengujian nilai F-statistik dalam penelitian ini diperoleh nilai sebesar 37,28 lebih besar dibandingkan dengan nilai Ftabel pada tingkat signifikansi $(\alpha) 5 \%$ yaitu 4,03 sehingga $\mathrm{H}_{0}$ ditolak dan $\mathrm{H}_{\mathrm{a}}$ diterima. Dengan demikian dapat disimpulkan bahwa bantuan langsung masyarakat dan swadaya masyarakat secara bersama-sama mempengaruhi jumlah desa tertinggal.

\section{Koefisien Determinasi $\left(R^{2}\right)$}

Pada hasil estimasi, $\mathrm{R}^{2}$ menunjukkan nilai 0,6034 . Hal ini mengindikasikan bahwa $60 \%$ jumlah desa tertinggal dipengaruhi oleh bantuan langsung masyarakat dan swadaya masyarakat sedangkan sisanya $40 \%$ dipengaruhi oleh faktor lain diluar model.

\section{Individual Effect}

Tabel 22 menunjukkan bahwa kabupaten yang memiliki efek terbesar terhadap desa tertinggal adalah Lampung Selatan dengan effect sebesar 7,347016 hal ini menunjukkan bahwa dengan adanya bantuan langsung masyarakat dan swadaya masyarakat akan tetap meningkatkan desa tertinggal di Lampung Selatan, karena dengan adanya bantuan langsung masyarakat dan swadaya masyarakat masih akan tetap meningkatkan desa tertinggal sebesar 7,34 desa. Begitu juga dengan kabupaten lainnya yang memiliki effect positif seperti Lampung Utara sebesar 6,33 persen, Tulang Bawang Barat sebesar 6,41 persen, Pesisir Barat sebesar 5,88 persen, Mesuji sebesar 4,99 persen, Lampung sebesar 5,87 persen, Tanggamus sebesar 4,04 persen dan Lampung Barat sebesar 3,97 persen. Efek positif tersebut mengindikasikan bahwa ada variabel lain yang mempengaruhi desa tertinggal.

Tabel. 22.

Individual Effect

\begin{tabular}{lrr}
\hline \multicolumn{1}{c}{ CROSSID } & \multicolumn{1}{c}{ Effect } & Total Effect \\
\hline Lampung Selatan & 3,402963 & 7,347016 \\
Lampung Utara & 2,392454 & 6,336507 \\
Lampung Barat & 0,029263 & 3,973316 \\
Lampung Timur & $-0,241736$ & 3,702317 \\
Lampung Tengah & 1,930272 & 5,874325 \\
Pesawaran & $-2,002201$ & 1,941852 \\
Pringsewu & $-3,027393$ & 0,916660 \\
Tanggamus & 0,096253 & 4,040306 \\
Tulang Bawang & $-1,178261$ & 2,765792 \\
Tulang Bawang & 2,463364 & 6,407417 \\
Barat & 1,055485 & 4,999538 \\
Mesuji & $-2,294867$ & 1,649186 \\
Way Kanan & 1,939410 & 5,883463 \\
Pesisir Barat
\end{tabular}

Sumber: Hasil Olahan Eviews 9, 2019

Sedangkan kabupaten yang secara negatif memiliki nilai terbesar dalam hasil Cross-section Random Effect adalah Pringsewu dengan nilai -3,03. Hal ini menunjukkan bahwa bantuan langsung masyarakat dan swadaya masyarakat akan menurunkan desa tertinggal sebesar 0,92 persen. Begitu juga dengan Way Kanan sebesar 1,65 persen, Pesawaran sebesar 1,94 persen, Tulang Bawang sebesar 2,76 persen, dan Lampung Timur sebesar 3,70 persen. Efek tersebut mengindikasikan bahwa tanpa bantuan langsung masyarakat dan swadaya 
masyarakat sangat diperlukan untuk mendorong penurunan desa tertinggal.

\section{SIMPULAN}

Program Gerbang Desa Saburai berhasil meningkatkan kesejahteraan dan kesempatan kerja masyarakat miskin di pedesaan dengan mendorong kemandirian dalam pengambilan keputusan dalam pengelolaan pembangunan, meningkatan partisipasi dan pemberdayaan masyarakat di wilayah perdesaan dalam pembangunan daerah, meningkatkan swadaya masyarakat dalam pelaksanaan dan pelestarian pembangunan dan mengentaskan desa tertinggal di Provinsi Lampung.

Bantuan Langsung Masyarakat dan Swadaya Masyarakat berpengaruh terhadap pengentasan desa tertinggal di Provinsi Lampung, semakin besar Bantuan Langsung Masyarakat dan Swadaya Masyarakat maka semakin banyak desa yang berubah status dari desa tertinggal menjadi desa kurang berkembang, berkembang, maju dan mandiri.

\section{Saran}

Perlunya dilakukan perbaikan dalam penjelasan Petunjuk Teknis Operasional (PTO), sosialisasi dan pendampingan dalam pengelolaan administrasi, perlunya pengawasan dan monitoring dari instansi masing-masing kabupaten dalam penyaluran dana dan perlunya peran Organisasi Perangkat Desa (OPD) dalam menentukan program yang sesuai dengan pembangunan Indeks Kemajuan Desa (IKD).

Program Gerbang Desa Saburai baik untuk pengentasan desa tertinggal, sehingga perlu tindaklanjut program yang sejenis agar dapat mengangkat status desa menjadi tidak lagi tertinggal.

\section{DAFTAR PUSTAKA}

Abdul Wahab, Solichin. 2012. Analisis Kebijakan: Dari Formulasi ke penyusunan Model-Model
Implementasi Kebijakan Publik. Jakarta: PT. Bumi Aksara.

Agusta I, Fujiartanto. 2014. Indeks Kemandirian Desa: Metode, Hasil, dan Alokasi Program Pembangunan. Jakarta (ID). Yayasan Pustaka Obor Indonesia.

Anwar A. 2005. Ketimpangan pembangunan wilayah dan perdesaan. Tinjauan Kritis. Bogor : P4W Press

Alamsyah M.N. 2011. Memahami Perkembangan Desa di Indonesia. Jurnal Fisip Unpad,. Volume 03 No. 02 Oktober 2011. ISSN 1411-3341.

Badan Perencanaan Pembangunan Nasional. 2004. Tata Cara Perencanaan Pengembangan Kawasan Untuk Percepatan Pembangunan Daerah. Direktorat Pengembangan Kawasan Khusus dan Tertinggal. Jakarta: BAPPENAS

Badan Pusat $\quad 2019$. http://www.bps.go.id

Bayu, Putu. Mahendra, Putra Yasa. Nyoman, Mahaendra.\& Yuliarmi, Ni Nyoman. (2017). Analisis Pengaruh Implementasi Program Nasional Pemberdayaan Masyarakat Mandiri Perkotaan (PNPM MP) Terhadap Produktivitas Kerja Dan Kesejahteraan Masyarakat Di Kecamatan Denpasar Utara. E-Jurnal Ekonomi dan Bisnis Universitas Udayana. Denpasar: 6.3 (2017): 1019-1048.

Budiarto, Tri, Eman Rustiadi, dan Arya Hadi Dharmawan. 2017. Perkembangsn dan Kemndirian Desa di Kabopaten Bogor, Provinsi Jawa Barat. Tata Loka Vol. 19 No. 3

Buku PTO. Gerbang Desa Saburai. Badan Pemberdayaan Masyarakat dan Pemerintahan Desa. Provinsi Lampung Effendi, Irwan. 2007. Meningkatkan Partisispasi Masyarakat Dalam pembangunan Melalui Program Pemberdayaan. Universitas Lampung. Hamidi, Hanibal.,dkk. 2015.Indeks Desa Membangun. Jakarta:Kementerian 
Desa, Pembangunan Daerah Tertinggal dan Transmigrasi.

Peraturan Gubernur Provinsi Lampung. Nomor 37 tahun 2015 tentang Program Membangun Desa Sai Bumi Ruwa Jurai Tahun 2015-2019.

Peraturan Menteri Desa, Pembangunan Daerah Tertinggal, Dan Transmigrasi No.1 Tahun 2005 Tentang Strategi Nasional Pembangunan Daerah Tertinggal, dan Transmigrasi

Peraturan Menteri Desa, Pembangunan Daerah Tertinggal, Dan Transmigrasi No.3 Tahun 2015 tentang Petunjuk Teknis Penentuan Indikator Daerah Tertinggal secara Nasional

Peraturan Presiden Republik Indonesia, Penetapan Daerah Tertinggal No 131
Tahun 2015, Tentang Penetapan

Daerah Tertinggal tahun 2015-2019 Prasetyanto PP, Eko. 2012. Dampak Alokasi Dana Desa Pada Era Desentralisasi Fiskal Terhadap Perekonomian Daerah Di Indonesia. Disertasi. I $\mathrm{PB}$, Bogor

Sumawinata, Sarbini. 2004. Politik Ekonomi Kerakyatan. Jakarta: PT. Gramedia Pustaka Utama.

Suroso. 2019. Eksistensi Pembangunan Masyarakat dan Desa di Kawasan Perkotaan Kabupaten Pati.

Todaro, Michael P. dan Stephen C. Smith. 2006. Pembangunan Ekonomi (edisi kesembilan, jilid I). Jakarta : Erlangga 